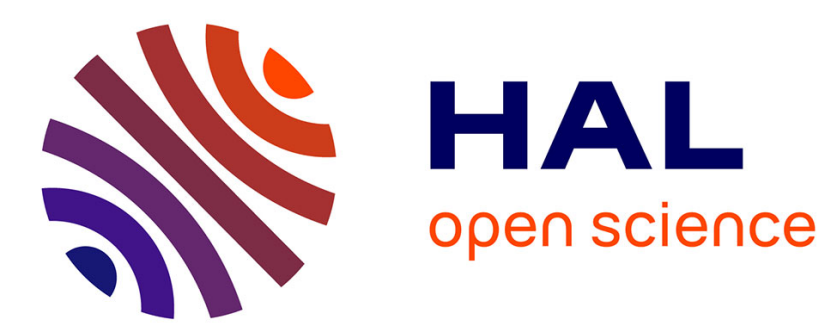

\title{
High pressure and temperature study of hydrogen storage material BHNH from calculations
}

\author{
M. Ramzan, R. Ahuja
}

\section{To cite this version:}

M. Ramzan, R. Ahuja. High pressure and temperature study of hydrogen storage material BHNH from calculations. Journal of Physics and Chemistry of Solids, 2010, 71 (8), pp.1137. 10.1016/j.jpcs.2010.03.021 . hal-00661909

\section{HAL Id: hal-00661909 \\ https://hal.science/hal-00661909}

Submitted on 21 Jan 2012

HAL is a multi-disciplinary open access archive for the deposit and dissemination of scientific research documents, whether they are published or not. The documents may come from teaching and research institutions in France or abroad, or from public or private research centers.
L'archive ouverte pluridisciplinaire HAL, est destinée au dépôt et à la diffusion de documents scientifiques de niveau recherche, publiés ou non, émanant des établissements d'enseignement et de recherche français ou étrangers, des laboratoires publics ou privés. 


\section{Author's Accepted Manuscript}

High pressure and temperature study of hydrogen storage material $\mathrm{BH}_{3} \mathrm{NH}_{3}$ from ab initio calculations

M. Ramzan, R. Ahuja

PII: S0022-3697(10)00067-3

DOI:

Reference: doi:10.1016/j.jpcs.2010.03.021 PCS 6130

To appear in:

Journal of Physics and

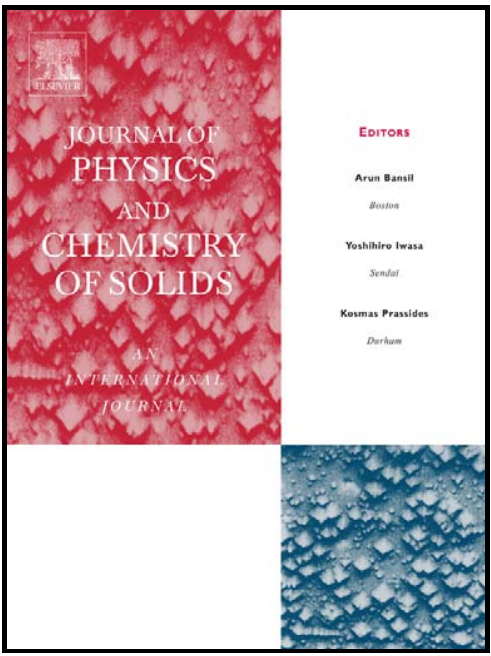

www.elsevier.com/locate/jpcs Chemistry of Solids

Cite this article as: M. Ramzan and R. Ahuja, High pressure and temperature study of hydrogen storage material $\mathrm{BH}_{3} \mathrm{NH}_{3}$ from ab initio calculations, Journal of Physics and Chemistry of Solids, doi:10.1016/j.jpcs.2010.03.021

This is a PDF file of an unedited manuscript that has been accepted for publication. As a service to our customers we are providing this early version of the manuscript. The manuscript will undergo copyediting, typesetting, and review of the resulting galley proof before it is published in its final citable form. Please note that during the production process errors may be discovered which could affect the content, and all legal disclaimers that apply to the journal pertain. 


\title{
High pressure and temperature study of hydrogen storage material $\mathrm{BH}_{3} \mathrm{NH}_{3}$ from ab initio calculations
}

\author{
M. Ramzan* \\ Condensed Matter Theory Group, Department of Physics and Materials Science, \\ Box 530, Uppsala University, SE-751 21 Uppsala, Sweden \\ R. Ahuja \\ Condensed Matter Theory Group, Department of Physics and Materials Science, \\ Box 530, Uppsala University, SE-751 21 Uppsala, Sweden and \\ Applied Materials Physics, Department of Materials and Engineering, \\ Royal Institute of Technology (KTH), SE-100 44 Stockholm, Sweden
}

(Dated: March 9, 2010)

\begin{abstract}
We report on $\mathrm{BH}_{3} \mathrm{NH}_{3}$, which is material that is considered promising to use as hydrogen storage, using density functional theory with generalized gradient approximation (GGA). We study the phase transition of $\mathrm{BH}_{3} \mathrm{NH}_{3}$ at high pressure and temperature. Our observed phase transition of $\mathrm{BH}_{3} \mathrm{NH}_{3}$ from body-centered tetragonal to orthorhombic at $\approx 220^{\circ} \mathrm{K}$ supports the recent and earlier studies. We observe the phase transformation of $\mathrm{BH}_{3} \mathrm{NH}_{3}$ at $\approx 11.5 \mathrm{GPa}$, which is in good agreement with experimental value. Specifically, we predict the phase trnasition at $\approx 11.5 \mathrm{GPa}$ to be orthorhombic to body-centered tetragonal on the basis of our first principles calculations.
\end{abstract}

PACS numbers: 33.15.Fm, 61.50.Ah, 61.66.Fn, 84.60.-h

Keywords: hydrogen storage, phase transition, high pressure

\footnotetext{
${ }^{*}$ Corresponding author. E-mail: muhammad.ramzan@fysik.uu.se
} 


\section{INTRODUCTION}

Hydrogen has been studied as environment friendly and efficient energy carrier in the search of alternative energy sources $[1,2]$. The reliable storage system is the key issue in the use of hydrogen as an alternate energy source. Nowadays, researchers have paid their attention on a solid state hydrogen storage material $\mathrm{BH}_{3} \mathrm{NH}_{3}$, because of its high volumetric and gravimetric properties (19.6 wt\%) [3-8], which exceeds the target (9 wt\%) for hydrogen storage systems, set by U.S. Department of Energy $[9,10]$. At moderate temperatures, hydrogen released irreversibly through thermolysis $[4,7,11]$ and dehydrogenation with the use of transition metal $[12,13]$ or acid $[14,15]$ catalysis, from $\mathrm{BH}_{3} \mathrm{NH}_{3}$. The thermal decomposition of $\mathrm{BH}_{3} \mathrm{NH}_{3}$ consists of three steps and the process completes with the release of all hydrogen atoms at $500^{\circ} \mathrm{C}$. The acidic catalyzed dehydrogenation requires a solvent, which reduces the gravimetric density. The release of hydrogen causes in polymerization to $\left(\mathrm{NH}_{2} \mathrm{BH}_{3}\right)_{n}$ and then to $(\mathrm{NHBH})_{n}[3-7]$. The rapid polymerization creates a difficulty for rehydrogenation. The released hydrogen is also contaminated with unwanted trace quantities of borazine and aminoborane [3-7]. In recent years, significant research efforts have been carried out to the efficient release of hydrogen from $\mathrm{BH}_{3} \mathrm{NH}_{3}$ by lowering the decomposition temperature and improving the discharge rate of hydrogen using the nanoscaffolds [16], ionic liquids [11] and acid [14, 15] or transition metal [12, 13] catalysts.

It is important to understand the geometric and electronic properties, which are responsible for the reactivity, inter and intramolecular interactions and stability, for the improvement of hydrogen absorption and desorption kinetics in ammonia borane. Therefore, the determination of accurate crystal structure of ammonia borane is necessary. High pressure studies are more helpful to understand the structural properties of hydrogen storage materials and can play an important role to improve the design of such materials [17]. Recently, Lin et al. [18] have reported three phase transitions of ammonia borane up to $22 \mathrm{GPa}$ on the basis of Raman spectroscopy. They [18] have observed the two new transitions of ammonia borane at approximately 5 and $12 \mathrm{GPa}$. Very recently, Hess et al. [19] have reported the structural evolution of ammonia borane from 15 to $340^{\circ} \mathrm{K}$ on the basis of neutron powder diffraction and molecular simulations. In this paper, we focus on the high pressure and temperature studies of the structural properties of ammonia borane on the basis of density functional theory calculations. We predict the orthorhombic to body-centered tetragonal 
phase transformation of ammonia borane at high pressure. Furthermore, we observe the temperature dependent phase transition of ammonia borane from body-centered tetragonal to orthorhombic structure on the basis of ab initio molecular dynamics calculations, which is in good agreement with the recent and earlier studies.

\section{STRUCTURAL AND COMPUTATIONAL DETAILS}

Ammonia borane has body-centered tetragonal structure and crystallized in the $I 4 \mathrm{~mm}$ space group No. 107 at ambient conditions, with the unit cell having two formula units [21, 22]. At $16^{\circ} \mathrm{K}, \mathrm{BH}_{3} \mathrm{NH}_{3}$ has been reported to has a orhorhombic structure and crystallized in the Pmn2 $2_{1}$ space group No. 31, having two molecules in the unit cell [23]. We have performed all the calculations with the use of projector-augmented wave (PAW) method [24] as implemented in the Vienna $A b$ initio Simulation Package (VASP) code $[25,26]$. We have used generalized gradient approximation (GGA) [27]. The chemically "active" electrons in the PAW calculations were N: $2 s^{2} 2 p^{3}$; B: $2 s^{2} 2 p^{1} ; \mathrm{H}: 1 s^{1}$. A $5 \times 5 \times 5 k$-points mesh generated by the Monkhorst-Pack method [28] was found sufficient to achieve convergence. All the structures had its total energy converged upto an accuracy of $0.005 \mathrm{eV}$. The kinetic energy cutoff of $520 \mathrm{eV}$ was found sufficient for the plane wave basis.

\section{RESULTS AND DISCUSSION}

For high pressure studies of $\mathrm{BH}_{3} \mathrm{NH}_{3}$, all calculations were performed at $0^{\circ} \mathrm{K}$. Our theoretical investigations were initiated by first determining the equation of state (EOS), using the internal energy of the crystal at different chosen volumes. We have obtained the equilibrium parameters and total energies by relaxing the bct and orthorhombic structures of $\mathrm{BH}_{3} \mathrm{NH}_{3}$ with respect to fractional atomic coordinates and cell parameters, with the use of, fully self-consistent $a b$ initio electronic structure calculations. We have compared the total energies for the relaxed tetragonal and orthorhombic structures by plotting the volume ratio versus total energy and the results are shown in fig. 1. From this it can be easily seen that at $\approx 33 \%$ compression, the body-centered tetragonal structure has become lower in energy, which is an evidence of structural phase transition from orthorhombic to tetragonal sructure at this compression. We have fitted the resulting energy versus volume data to an 
integrated third-order Birch-Murnaghan equation of state (EOS). The pressure was calculated by taking the volume derivative of the total energy for the both structures. For the further authentication of our results, we have calculated the structural enthalpies for the both structures and plotted it as a function of pressure. The results have been displayed in fig. 2. The calculated phase transition pressure has been found $\approx 11.5 \mathrm{GPa}$. Our calculated phase transition pressure is in good agreement with experimental value of $\approx 12 \mathrm{GPa}$ [18]. Temperature dependent studies were carried out, using the ab initio molecular dynamics simulations for orthorhombic and bct structures of $\mathrm{BH}_{3} \mathrm{NH}_{3}$. The $5 \times 10^{3}$ ionic steps with a time step of 1.0 fs were used in our calculations. The simulations were carried out on a series of different temperatures. A schematic of our results is presented in fig.3, and the phase transformation of $\mathrm{BH}_{3} \mathrm{NH}_{3}$ from body-centered tetragonal $I 4 m m$ to orthorhombic Pmn $2_{1}$ at $\approx 220^{\circ} \mathrm{K}$ can be seen clearly. Our estimated phase transition of ammonia borane at $\approx$ $220^{\circ} \mathrm{K}$ is in good agreement with recent and earlier studies, at $\approx 225^{\circ} \mathrm{K} \quad[19,20]$.

\section{CONCLUSIONS}

In summary, we have presented the sructural properties of $\mathrm{BH}_{3} \mathrm{NH}_{3}$ for the ground state, and high pressure and temperature phase, from our systematic first-principles calculations. We have estimated the sructural enthalpies for the bct and orthorhombic structures of $\mathrm{BH}_{3} \mathrm{NH}_{3}$. We have observed the phase transition of $\mathrm{BH}_{3} \mathrm{NH}_{3}$, at high pressure and temperature, which supports the earlier studies. Our estimated phase transition temperature of $\mathrm{BH}_{3} \mathrm{NH}_{3}$ from body-centered tetragonal $I 4 m m$ to orthorhombic $P m n 2_{1}$ is $\approx 220^{\circ} \mathrm{K}$, which supports the recent and earlier studies. In particular, we have predicted the phase transformation of $\mathrm{BH}_{3} \mathrm{NH}_{3}$ to be orthorhombic Pmn2 $2_{1}$ to body-centered tetragonal $I 4 m m$ at $\approx$ 11.5 GPa. Finally, our work will be helpful to understand the internal structural properties of $\mathrm{BH}_{3} \mathrm{NH}_{3}$ to make it more promising hydrogen storage material and can play an important role to improve the design of such materials.

\section{Acknowledgments}

We would like to acknowledge STINT, VR and Futura for financial support. M. Ramzan is thankful to the Higher Education Commission of Pakistan for financial support. SNIC 
and UPPMAX have provided computing time for this project. 
[1] L. Schlapbach, and A. Zuttel, Nat. Mater. 414, 353-358 (2001).

[2] M. S. Dresselhaus, and I. L. Thomas, Nat. Mater. 414, 332-337 (2001).

[3] A. C. Stowe, W. J. Shaw, J. C. Linehan, B. Schmid, and T. Autrey, Phys. Chem. Chem. Phys. 9, 1831 (2007).

[4] M. G. Hu, R. A. Geanangel, and W.W. Wendlandt, Thermochim. Acta 23, 249 (1978).

[5] V. Sit, R. A. Geanangel, and W. W. Wendlandt, Thermochim. Acta 113, 379 (1987).

[6] G. Wolf, J. Baumann, F. Baitalow, and F. P. Hoffmann, Thermochim. Acta 343, 19 (2000).

[7] F. Baitalow, J. Baumann, G. Wolf, K. Jaenicke-Rößler, and G. Leitner, Thermochim. Acta 391, 159 (2002).

[8] M. Ramzan, F. Silvearv, A. Blomqvist, R. H. Scheicher, S. Lebgue, and R. Ahuja Phys. Rev. B 79, $132102(2009)$

[9] S. Satyapal, J. Petrovic, C. Read, G. Thomas, and G. Ordaz, Catal Today 120, 246-256 (2007).

[10] C. W. Hamilton, R. T. Baker, A. Staubitz, and I. Manners, Chem. Soc. Rev. 38, 279-293 (2009).

[11] M. E. Bluhm, M. G. Bradley, R. Butterick, U. Kusari, and L. G. Sneddon, J. Am. Chem. Soc. 128, 7748 (2006).

[12] R. J. Keaton, J. M. Blacquiere, and R. T. Baker, J. Am. Chem. Soc. 129, 1844 (2007).

[13] F. Y. Cheng, H. Ma, Y. M. Li, and J. Chen, Inorg. Chem. 46, 788 (2007).

[14] H. C. Kelly, and V. B. Marriott, Inorg. Chem. 18, 2875 (1979).

[15] F. H. Stephens, R. T. Baker, M. H. Matus, D. J. Grant, and D. A. Dixon, Angew. Chem. Int. Ed. 46, 746 (2007).

[16] A. Gutowska, L. Li, Y. Shin, C. M. Wang, X. S. Li, J. C. Linehan, R. S. Smith, B. D. Kay, B. Schmid, W. Shaw, M. Gutowski, and T. Autrey, Angew. Chem. Int. Ed. 44, 3578-3582 (2005).

[17] W. L. Mao. and H. K. Mao, Proc. Natl. Acad. Sci. USA. 101, 708-710 (2004).

[18] Y. Lin, W. L. Mao, V. Drozd, J. Chen, and L. L. Daemen, J. Chem. Phy. 129, 234509 (2008).

[19] N. J. Hess, G. K. Schenter, M. R. Hartman, L. L. Daemen, T. Proffen, S. M. Kathmann, C. J. Mundy, M. Hartl, D. J. Heldebrant, A. C. Stowe, and T. Autrey, J. Phys. Chem. A, 113, 
19, 5723-5735 (2009).

[20] W. T. Klooster, T. F. Koetzle, P. E. M. Siegbahn, T. B. Richardson, and R. H. Crabtree, J. Am. Chem. Soc. 121, 6337 (1999).

[21] C. F. Hoon, and E. C. Reynhardt, J. Phys. C 16, 6137 (1983).

[22] M. E. Bowden, G. J. Gainsford, and W. T. Robinson, Aust. J. Chem. 60, 149 (2007).

[23] J. B. Yang, J. Lamsal, Q. Cai, W. J. James, and W. B. Yelon, Appl. Phys. Letters 92, 091916 (2008).

[24] P. E. Blöchl, Phys. Rev. B 50, 17953 (1994).

[25] G. Kresse and J. Furthmüller, Comput. Mater. Sci. 6, 15 (1996).

[26] G. Kresse and D. Joubert, Phys. Rev. B 59, 1758 (1999).

[27] J. P. Perdew and Y. Wang, Phys. Rev. B 45, 13244 (1992).

[28] H. J. Monkhorst and J. D. Pack, Phys. Rev. B 13, 5188 (1976). 


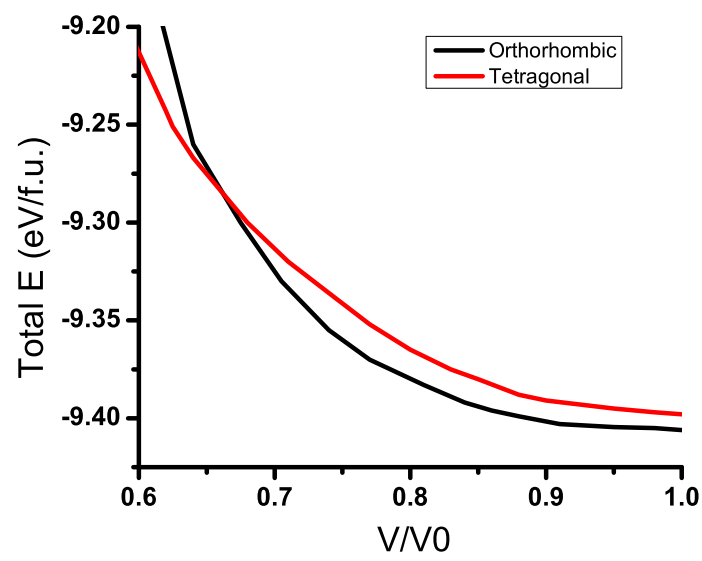

FIG. 1: Computed variations in the total energies with volume compression for the orthorhombic and tetragonal structures of $\mathrm{BH}_{3} \mathrm{NH}_{3}$.

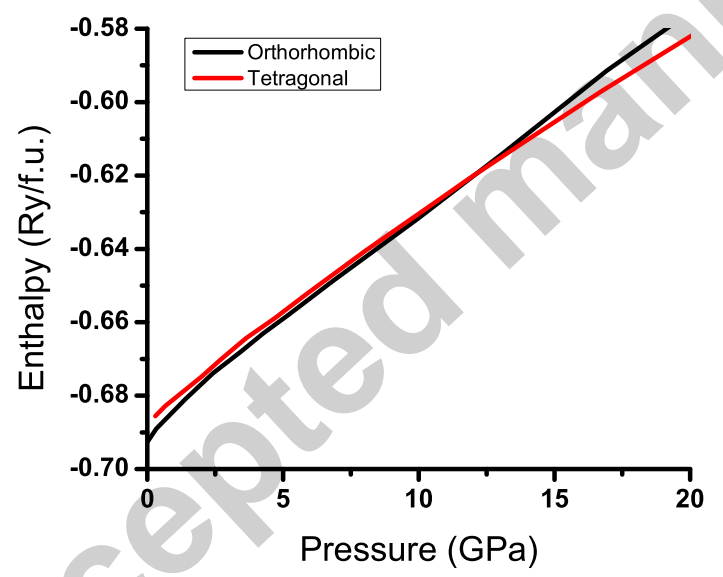

FIG. 2: Phase transition of $\mathrm{BH}_{3} \mathrm{NH}_{3}$ from orthorhombic to tetragonal structure at $\approx 11.5 \mathrm{GPa}$, determined by our ab initio calculations. 


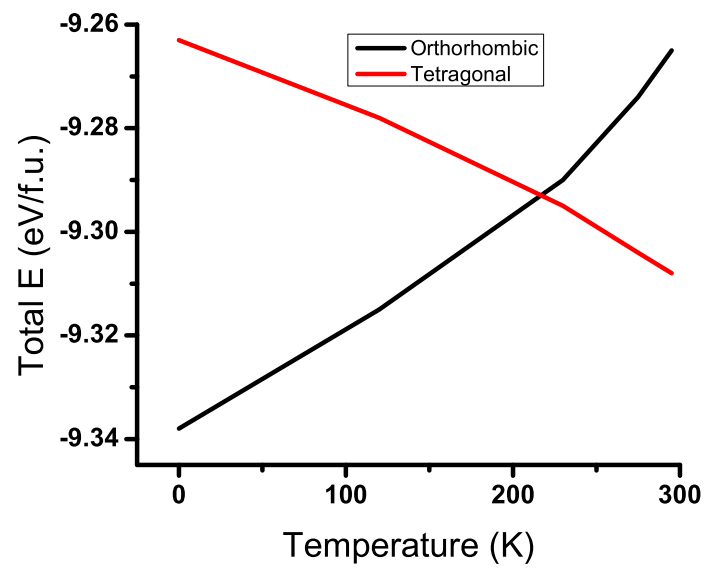

FIG. 3: Phase transition of $\mathrm{BH}_{3} \mathrm{NH}_{3}$ from tetragonal to orthorhombic structure at $220^{\circ} \mathrm{K}$, estimated by our ab initio molecular dynamics calculations. 